\title{
Societal Dimension of Energy Consumption - Exploring Environmental Inequality in China
}

\author{
Guiying $\mathrm{Cao}^{1}$, Junlian $\mathrm{Gao}^{2}$, Ming Ren ${ }^{2}$, Tatiana Ermolieva ${ }^{1}$, Xiangyang $\mathrm{Xu}^{2} \&$ Elena Rovenskaya ${ }^{1}$ \\ ${ }^{1}$ International Institute for Applied System Analysis, Laxenburg, Austria \\ ${ }^{2}$ Center for Resources and Environment Policy Research, School of Management, China University of Mining and \\ Technology, Beijing, China \\ Correspondence: Guiying Cao, International Institute for Applied System Analysis, Laxenburg, Austria.
}

Received: November 15, 2017

Accepted: December 4, 2017

Online Published: December 17, 2017

doi:10.5430/rwe.v8n2p66

URL: https://doi.org/10.5430/rwe.v8n2p66

\begin{abstract}
From the social-ecological nexus perspective, environmental inequality is embedded in its root of social problem arising from income inequality. "The urgent global challenges of sustainability and equity must be addressed together" (IPCC2011). This paper intends to explore the link between house income inequality and environmental vulnerability in Rural of China. In the process of rural to urban dominated economy transformation, social structures are changing, and ecosystems are facing stress. Given China's dynamic economic and environmental situation, we aim to provide an assessment in the inequality of energy use and environmental effects in two different systems of urban and rural region in China. The paper deals with three questions: 1. how has household expenditure linked with the energy use directly and indirectly; 2 . how has China challenged by inequalities between rural and urban household on the residential energy consumption; 3. how high is the emission estimated in the rural residential energy use? The analysis results indicate obviously that almost half rural family still use no-commercial energy and thus coal is the main commercial energy sources; the per capital $\mathrm{CO}_{2}$ emissions of rural region is much higher than urban region, which is driven by low energy efficiency and less advanced public infrastructure. It address the equity issues that policy should focus on energy affordability and promoting a transition away from biomass to other modern energy sources in rural China. In the paper, the input-output table is employed for accounting the indirect residential energy use and emissions, which is associated with the eight sectors of household expenditure. The data sources are from various household serveries and energy statistics in the period of 1990 to 2016.
\end{abstract}

Keywords: environmental inequality, energy consumption, $\mathrm{CO}_{2}$ mission, input-output table, rural/urban household

\section{Introduction}

Energy is an essential component of economic development, and decisions and practices of energy sector will play a central role in determining the sustainability of development in every country and region. At the national and international levels, energy and environmental policies are being shaped in response to sustainability development. These include improving the energy efficiency of transport and power generation; financing the expansion of the electricity, oil, and gas industries; addressing global warming and reducing pollution caused by fossil fuels. An equally important but often been neglected aspect of energy production and use is the lack of access for rural populations to affordable "modern" energy sources, such as electricity, liquid fuels, and modern biomass. In developing countries, this situation can have serious social, economic, and environmental consequences (Douglas \& Willem, 1996).

In recent energy management literatures, there is a growing interest in social dimension of energy. Some scholars call for a new approach for energy policy, which contribute to an extended consideration of technology and cost, and encompass the broader societal dimensions of energy change. Clark A. Miller (Miller, 2013) argued, in the process of energy transformation, three critical intersecting aspects should be addressed: the first one is the idea of energy infrastructures, which energy systems are at once relatively hidden from public scrutiny and yet deeply structuring of social and economic arrangements that can stifle alternatives without our realizing ? The second one is the idea of energy epistemic. Who knows about energy systems, what and how do they know, and whose knowledge counts in governing and reshaping energy futures? The third one is the idea of energy justice, it means to implement a just energy transformation that will neither perpetuate the existing negative impacts of energy production and use nor 
create new ones. Regarding to the energy justice, furthermore, Dara O'Rourke1 and Sarah Connolly (Dara \& Sarah, 2003) indicated, it is energy systems often create inequalities in the distributions of harms and benefits, the dangerous pollutants associated with energy are often concentrated in locations or groups with little wealth or political power.

In the annual report (IPCC, 2011), with an overview of the urgent global challenges of sustainability and equity, IPCC indicated that the urgent global challenges of sustainability and equity must be addressed together. It is possible to envision an evolution toward equitable and sustainable development, its underlying determinants are also deeply embedded in existing societal patterns that are unsustainable and highly inertial. A useful set of determinants from which to examine the prospects for and impediments to SD and equity are: the legacy of development relations; governance and political economy; population and demography; values and behavior; human and social capital; technology; natural resource endowments; and finance and investment.

Energy inequalities often find a reflection in income inequalities and regional inequalities in the process of industrial transition of developing countries. The deepening disparities and energy inequalities may lead to further disempowerment of those who are already at a disadvantage and greater social unrest in the future. This paper, we highlight on the China case with aspect of energy inequality between rural and urban at the aggregated household level. It intends to explore the link between household income inequality and environmental vulnerability in Urban and Rural of China, we aim to provide an assessment and comparison in the energy inequalities and environmental effects in two different systems of urban and rural region in China. Addressing the following questions: 1.How has household expenditure linked with the energy use directly and indirectly; 2 . How has China challenged by inequalities between rural and urban household on the residential energy consumption; 3. How high is the emission estimated in the rural residential energy use? 4 . What should the proper policy response for environmental inequality in rural region with a sustainable manner. In the analysis, the input-output table is employed for accounting the indirect residential energy use and residential emissions, which is associated with the eight sectors of rural household expenditure. The data sources are various household serveries and energy statistics from 1990 to 2015.

The paper is organized as follows. Following the introduction, section 2 exposes the trend of household income and residential energy consumption; section 3 estimates emission impact of rural residential energy use in comparing with urban household energy; section 4 Conclusion - rural sustainable energy consumption

\section{Household income and Residential Energy Consumption}

\subsection{Urban and Rural Gap in Income and Expenditure}

During the past three decades China's economic growth has been among the fastest in the world. At the same time the country experienced one of the fastest increasing in income and wealth inequality countries in the world. The income gap between urban households and rural households increased significantly from 1990s, as shown in Figure 1 and table1. Urban households spent 21392 Yuan (2.32 times) more than rural households and urban households received 31195 Yun (2.73 times) more in yearly income than rural households in 2015. This urban-rural income gap has played an increasingly important role in income inequality in China as a whole.

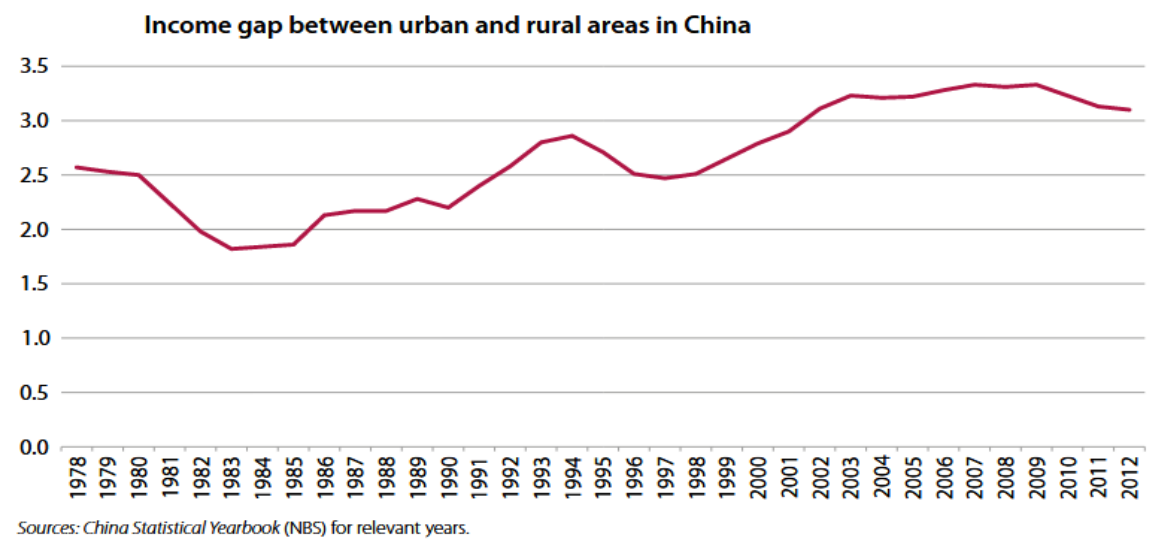

Figure 1. Ratio of real urban to real rural per capita income, 1978-2012 
The Table 1 highlights important differences between consumer expenditures by rural and urban households in 2015 :

Table 1. Urban and rural household income and expenditure 2015 (per capita), Yuan

\begin{tabular}{llll}
\hline 2015 & urban & rural & U/R \\
\hline Per capita disposable income & 31195 & 11422 & 2.73 \\
Per capita consumption expenditures & 21392 & 9223 & 2.32 \\
Per capita food tobacco expenditures & 6360 & 3048 & 2.09 \\
Per capita clothing expenditures & 1701 & 550 & 3.09 \\
Per capita expenditures & 4726 & 1926 & 2.45 \\
Per capita expenditures for goods and services & 1306 & 546 & 2.39 \\
Per capita expenditures for transportation and communication & 2895 & 1163 & 2.49 \\
Per capita expenditures for education culture, and entertainment & 2383 & 969 & 2.46 \\
Per capita expenditures for health care & 1443 & 846 & 1.71 \\
Per capita expenditures for other goods and services & 578 & 174 & 3.32 \\
\hline
\end{tabular}

Sources: 2016 statistics year book

\subsection{The Linkage of Expenditure Types, Energy Resources and Energy Emission in Household}

With the respect of household expenditure and energy consumption, the direct and indirect $\mathrm{CO}_{2}$ emission from household consumption accounted about $40 \%$ of total carbon emissions from primary energy utilization in China from 1990 to 2012. The increase of household consumption per capita, residential building, and dramatic increasing car users all contribute to an increase of indirect carbon emissions, which are derived by the increasing income of per capital of both rural and urban region. Consequently, the expenditure of household has promoted household energy consumption, hence is of great significance for $\mathrm{CO}_{2}$ emission. The linkage of expenditure-energy use-emission in household is illustrated in the Figure 2.

Figure 2, shows the framework how the 8 type of items of household expenditure are associated with major types of energy, in particular to food, housing consumption, transportation, and communication have strongly effected the energy use. From Figure 2 we see that residential energy use includes direct energy use and indirect energy use. The direct energy use is relative to the energy which the resident buy and consume directly for cook, heat, light, travel, etc.; the indirect energy use is relative to the energy which caused during the lifecycle of the commodities (Reinders, Vringer \& Blok, 2003). The production, processing, supply, disposal of commodities will lead to extensive energy consumption, so the resident expenditure on commodities will indirectly bring out energy use (EIA, 1995). 


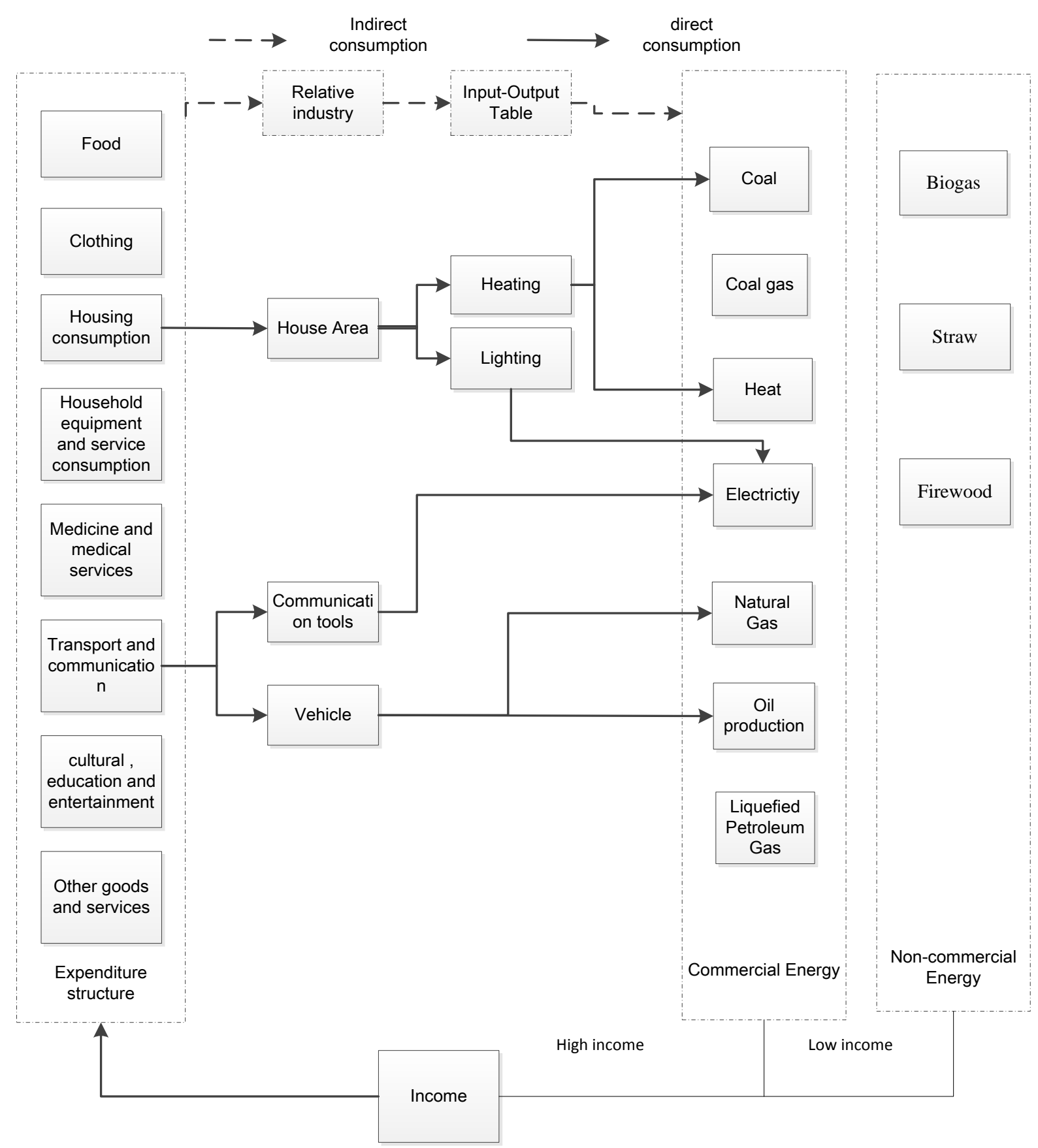

Figure 2. The relationship between per capital income, household expenditure and energy use

\subsection{Rural and Urban Residential Energy Use}

The increase of household consumption per capita has provided residents with more options in how they spend on transportation as well as housing, consequently dramatic increase energy use, which all contribute to an increase of direct and indirect carbon emissions.

\subsubsection{Indirect Energy Use}

In 2011, indirect Energy used by rural households has reached 378.41 millions ton coal equivalent, taking account of $10.87 \%$ in the total energy use of China. Compared with 1990, it was 279.49 million ton coal equivalent, taking account $30.14 \%$. While urban household shared the indirect energy use with $28.10 \%$ in the total energy use in 2011 , 
the number was $23.90 \%$ in 1990, the rural residential energy use was just 1/3 of its urban household in 2011.

\subsubsection{Direct Energy Use and Energy Structure}

From 1990 to 2011, direct rural household energy use has become more diversified and commercialized. The use of electricity, petroleum products, and liquefied petroleum gas have been gradually increased (see Figure 3). In the structure of direct rural residential energy use, coal is still the main commercial energy source, although it was reduced from $98.0 \%$ to $95.5 \%$ in sharing of total residential energy use comparing 1990 and 2011. The share of the electricity kept rising, which has reached $28.38 \%$ in 2011, which is a rise by nearly 6 times from 1990. In 2011, $10.30 \%$ of the total direct energy use is the oil production, three times as much as in 1990. The liquefied petroleum gas is same as the oil has slightly increased since 1990s.

While for urban household energy direct energy resources, the coal has been reduced from $95.38 \%$ in 1990 to 19.30 , but the electricity has been increased from $3 \%$ to 35.42 in total energy residential share during the same period.

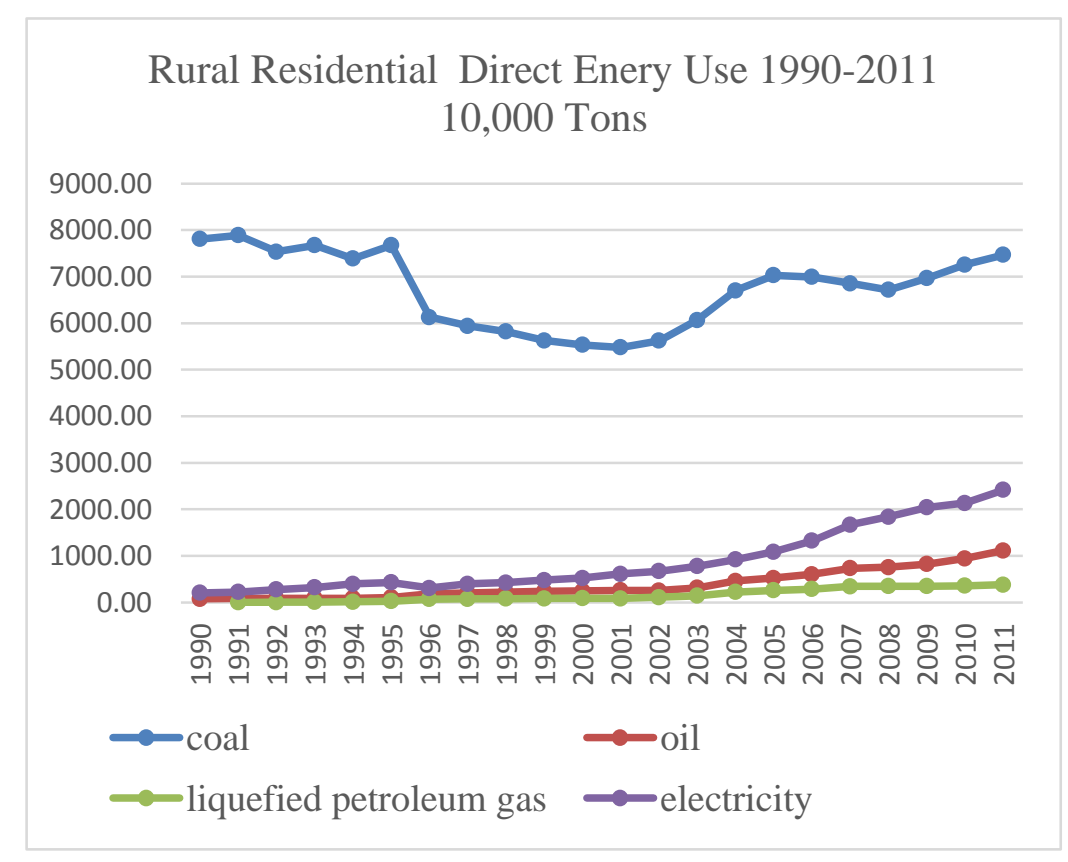

Figure 3. Trend of rural residential direct energy use 1990-2011

Sources: Energy Balance Table from Energy Statistic Yearbook 1991-2012

\subsubsection{Commercial Energy and Non-commercial Energy}

Other important aspect is a change of sharing the commercial and non-commercial Energy in terms of household energy sources, the figure 4 indicates the rural household energy sources in share of the commercial energy is stable around $40 \%$ (see fig.4). The use of non-commercial energy such as straw and firewood is till major rural residential energy resource, the proportion of no-commercial energy by rural household has been keep consistent with sharing of $43 \%$ in total energy use over the last 20 years. Because of the traditional use of non-commercial energy-direct burning, the non-commercial energy efficiency is lower than the commercial energy. Coal is still the main type of commercial energy use for rural resident, which is used for cooking and heating. 


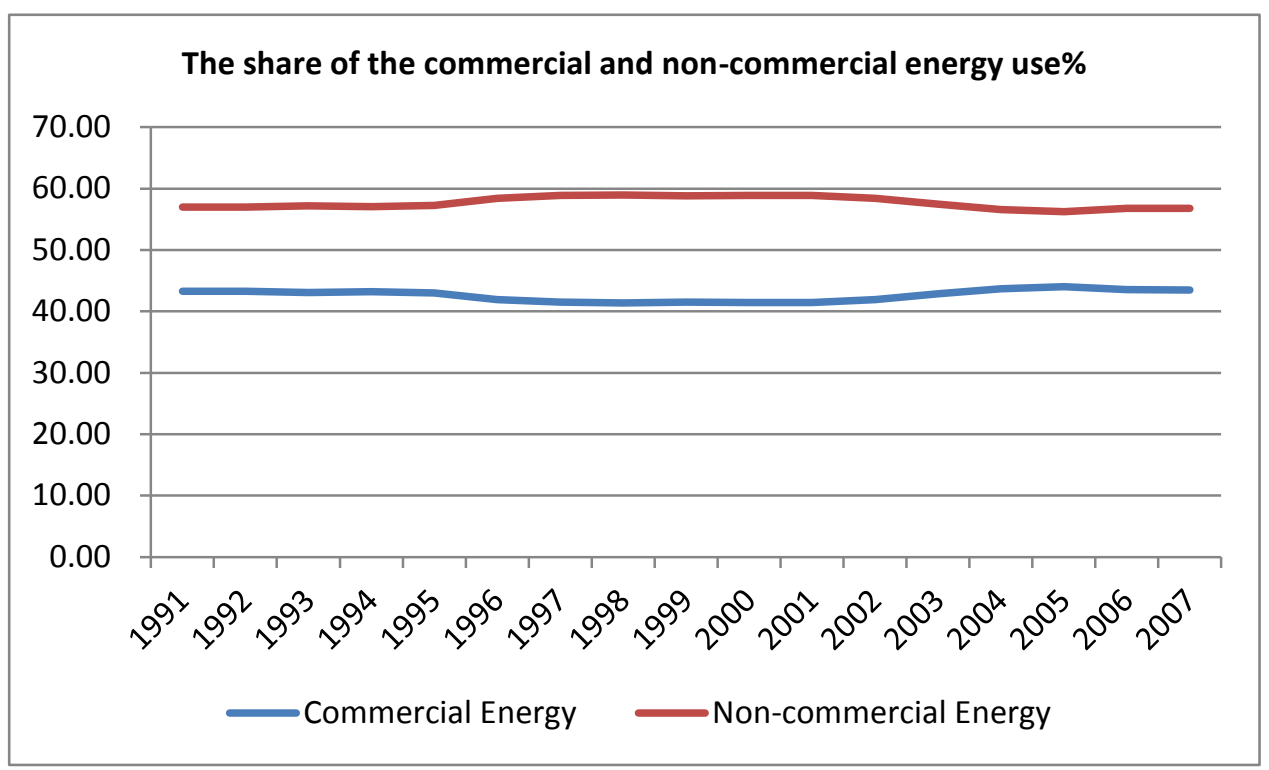

Figure 4. Rural commercial and non-commercial energy structure change 1991-2007

Sources: Energy Balance Table from Energy Statistic Yearbook 1991-2012

\subsubsection{Per Capital Energy Use}

Per capita rural household energy use reached $159.49 \mathrm{Kg}$ coal equivalent, while in urban region, per capita of urban household energy use was $231.94 \mathrm{~kg}$ coal equivalent in 2011. Although urban household per capital energy has been much higher than rural region, urban energy use is efficient because rural residents rely on low quality energy. In terms of increasing rate, the annual increasing rate of rural per capital energy use is $2.74 \%$ from 1990 to 2011, the urban per capital annual increased rate has been lower than rural region with $2.25 \%$.

\section{Estimating Environmental Impact of Rural Residential Energy Use}

The assessment includes direct and indirect energy uses with addressing on $\mathrm{CO}_{2}$ emission.

\subsection{Methodology and Date}

\subsubsection{Direct Emission Calculation}

By using 15 kinds of household energy (physical quantity) from the energy balance table of the Chinese Energy Statistical Yearbooks from 1991- 2012, we calculate the direct emission. The formula (1) is for the direct emission accounting:

$$
C E^{d i r}=\sum_{i} C E_{i} * E_{i}
$$

Where $C E^{d i r}$ refers to the direct $\mathrm{CO}_{2}$ emission, $i$ refers to a type of household energy, $C E_{i}$ refers to the

emission coefficients of household energy $i, E_{i}$ refers to household energy $i$.

\subsubsection{Indirect Emission Calculation}

Input-output analysis is developed by Wassily Leontief (Wassily, 1936) has often been used for quantifying the indirect energy consumptions and emission (Manfred, Mette \& Claude, 2006; Maurizio, Alessandra \& Sonia, 2013; State Statistical Bureau of China, 1991-2012). The accounting process are as follows:

1) To calculate the direct emission intensity based on the energy balance table and the input value by the industrial sectors, the formula is shown in (2); 


$$
C I_{t}^{d}=\frac{\sum_{i} C E_{i} * E_{t}^{i}}{O_{t}}
$$

Where $C I_{t}^{d}$ refers to the direct emission intensity of sector $t, C E_{i}$ refers to the emission coefficients of energy $i$,

$E_{t}^{i}$ refers to the consumption of energy $i$ in the sector $t . O_{t}$ refers to the outputs of sector $t$.

2) To calculate the cumulative intensity of carbon emission

The cumulative carbon intensity derived from formula (3):

$$
C I^{f}=C I^{d} *(1-A)^{-1}
$$

Where $C I^{f}$ refers the final carbon intensify matrix, $C I^{d}$ donates direct carbon intensity which are calculated as ratio of the direct carbon to total inputs, $A$ is the direct requirements matrix describing the relationship between all sectors of the economy.

The input-output tables' sectors were reclassified into 29 sectors in order to match the emission intensity results, which obtained from step 1). In this step accounting, we ignored the international trade.

In dealing with the consistency between five year input \& output table and the annual based expenditure data, it is important to adjust the emission intensity with an annual base. As the input-output table issues by the Chinese Statistics office only every five years, which are 1992, 1997, 2002, 2007, we use the linear interpolation method to smooth the emission intensity for every year from 1990-2011, which can help us to estimate the emission with an annual based.

To account the rural residential emission by 8 types of rural household expenditures, we distribute the cumulative intensity of carbon emission by 29 sectors into the 8 types of rural household expenditure. See Table 2. In dealing with the multi-industrial sectors which are filled in one type of household expenditure, for such case we use the weighted average method.

\begin{tabular}{|c|c|}
\hline Expenditure Item & Related Sectors of input-output tables \\
\hline Food & $\begin{array}{l}\text { Food manufacturing and tobacco processing industry; Accommodation and } \\
\text { catering; Agriculture, forestry, } \\
\text { animal husbandry and fishery }\end{array}$ \\
\hline Clothing & Textile; Garment leather down and Related products \\
\hline Housing & $\begin{array}{l}\text { Non-metallic mineral products industry; Coal mining and washing; Oil and gas } \\
\text { exploration industry; Gas production and supply; Electricity; Heat production and } \\
\text { supply industry; Water production and supply industry }\end{array}$ \\
\hline $\begin{array}{l}\text { Household } \\
\text { equipment and } \\
\text { service consumption }\end{array}$ & $\begin{array}{l}\text { Wood processing and furniture manufacturing; Fabricated Metal Products } \\
\text { Electrical machinery and equipment manufacturing }\end{array}$ \\
\hline Health care & $\begin{array}{l}\text { Medical and pharmaceutical products; General, special equipment manufacturing } \\
\text { industry }\end{array}$ \\
\hline $\begin{array}{l}\text { Transport and } \\
\text { communication } \\
\text { services }\end{array}$ & $\begin{array}{l}\text { Electrical machinery and equipment manufacturing; Transportation Equipment } \\
\text { Manufacturing; Electronic and communication equipment manufacturing } \\
\text { Petroleum processing and coking; Transportation, storage and postal services }\end{array}$ \\
\hline $\begin{array}{l}\text { Cultural, education } \\
\text { and entertainment }\end{array}$ & $\begin{array}{l}\text { Paper printing and Educational and Sports Goods; Measuring Instruments and } \\
\text { Office Machinery }\end{array}$ \\
\hline $\begin{array}{l}\text { Other goods and } \\
\text { services }\end{array}$ & Wholesale and retail trade; Other indu \\
\hline
\end{tabular}

Table 2. Combining the industrial sectors of the input-output table with 8 category of household expenditure 
3) To account the rural residential indirect emission by the per capital and total rural population

$$
C E^{\text {ind }}=\sum_{i}\left(C I_{i}^{f} * E N_{i}\right) \cdot P
$$

Where $C E^{\text {ind }}$ indicates the indirect $\mathrm{CO}_{2}$ emission, $i$ refers to the kind of expenditure item, $C I_{i}^{f}$ refers to the final or cumulative carbon intensity of expenditure item $i, E N_{i}$ refers to expenditure $i, P$ refers to the number of rural residents. Due to the expenditure data is based on the current price, for the accounting the emission, we adjusted the expenditure (Value) based on the year of input-output tables (1992, 1997, 2002, 2007). For example we should adjust the expenditure in 2009 on the baseline of 2007 by CPI as to eliminate the factors of inflation on the expenditure data.

\subsubsection{Data Sources}

All the analysis in this paper is based on the available data from the National Bureau of Statistics of China in 1992, 1997, 2002, 2007, and 2016, so we analyse carbon emissions from household during 1991 to 2011. The energy sectors include coal, oil and gas, petroleum products, electricity, and heat. Energy consumption data from 1990 to 2011 are taken from the China Energy Statistical Yearbook (State Statistical Bureau).The expenditure of rural household data are taken from the rural household survey (1995, 2000, 2005, 2010, and for 2011 taken from the China statistical Yearbook). The Rural population data and rural CPI are taken from China Statistical Yearbook (1991-2016), Energy emission coefficients derived from the "Provincial Greenhouse Gas Inventory Preparation Guide"(China NDRC, 2011).

\subsection{Accounting Results - Rural Household Energy Emission}

Due to the increased energy consumption, the per capita direct energy emission had a rise by more than 3 times (Figure 5). As the improvement of the life quality in rural, more and more people choose to use electricity to cook and heat, the annual increase rate of electricity consumption is $10.29 \%$ from 1990 to 2011, especially since 2000, the annual increase rate is $13.57 \%$. In 2012 , the thermal power capacity take account for $71.5 \%$, which made the electricity emission factor is high, the electricity emission factor is $0.9805 \mathrm{~kg} / \mathrm{Kwh}$.

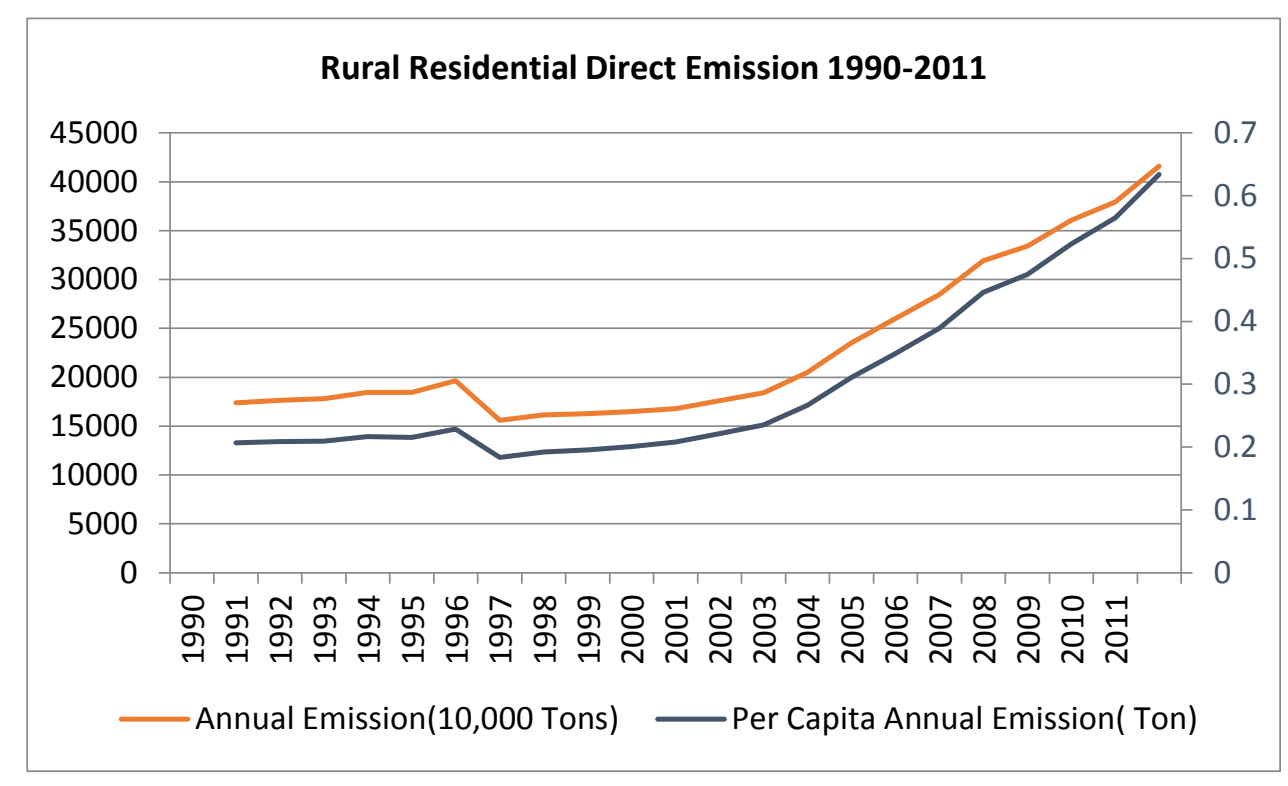

Figure 5. Rural residential direct emission and per capital emission

To control the emission in rural region, it is necessary to calculate the non-commercial energy emission since it is the 
main energy and the main source of the emission in rural China (see Figure 6). The Figure 7 tells that the non-commercial energy emission has even increased since 2002, which requests the mitigation solution for control the emission.

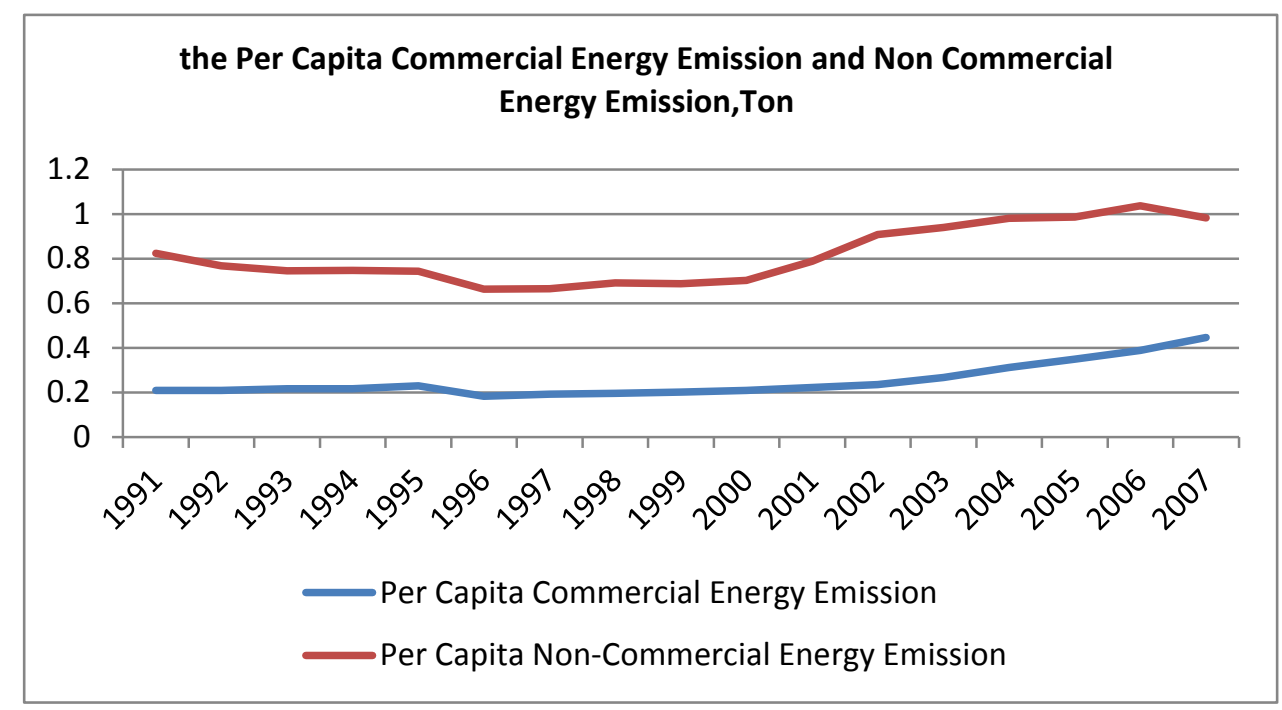

Figure 6. The per capita commercial and non-commercial energy emission

The indirect per capita emission is much higher than the direct emission in rural. (See Figure 7) The Figure 8 indicates that the indirect per capita annual emission has strongly increased since 1995 .

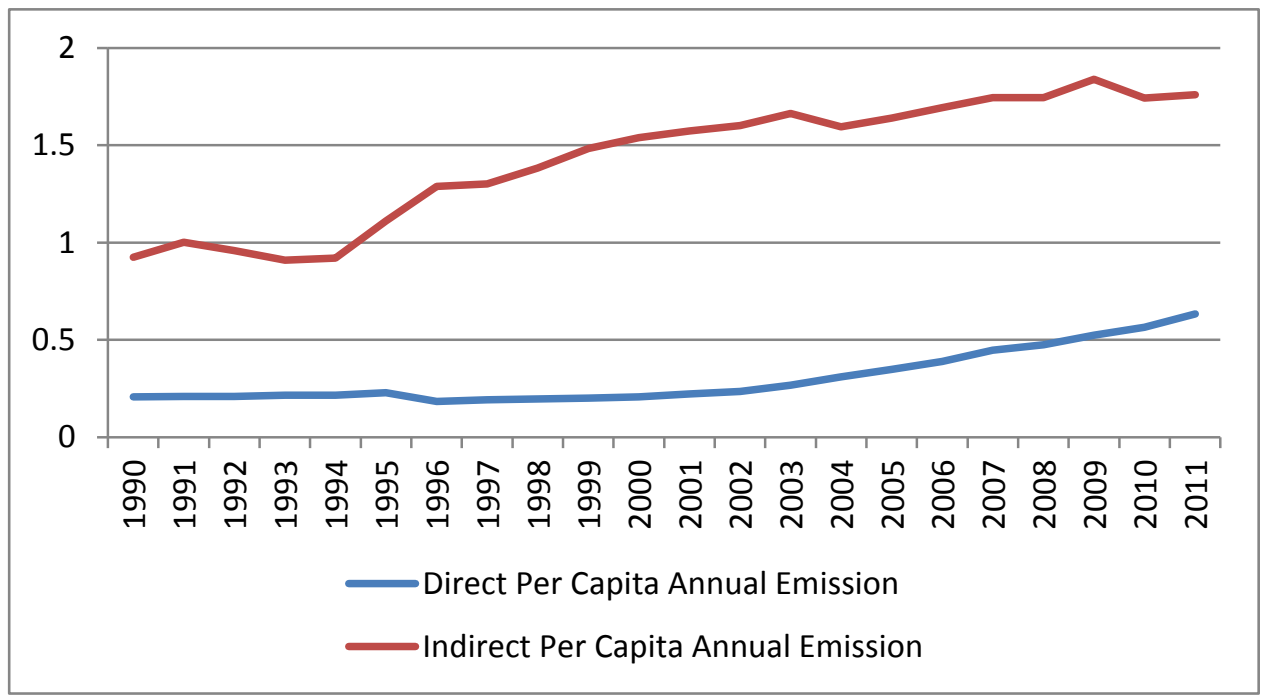

Figure 7. The direct per capita emission and the indirect per capital emission

From the Figure 8, we can see emission from food and housing is the main source of the indirect emission. The general trend of food emissions is inverted U-shaped from 1990-2011, from 1990-2010 is increased by $22.81 \%$, the emission intensity contributed $-100.90 \%$, and the expenditure contributed $123.71 \%$. While from 2000 to 2011 , the number has decreased by $65.64 \%$, the emission intensity contributed $-185.52 \%$, while the expenditure contributed $119.88 \%$. That is to say from 1990 to 2000, the contribution of increased energy efficiency didn't offset the contribution of the increased expenditure, but from 2000-2011, the increase energy efficiency plays an important role on the decreased emission from food. The emission from housing has increased very fast in the last decades. From 1990 to 2000 , it was increased by $39.03 \%$, in which the increased emission intensity contributed $-99.75 \%$, and the 
expenditure contributed $138.79 \%$. While from 2000 to 2011, it was increased by $96.28 \%$, in which the increased emission intensity contributed $-122.40 \%$, and the expenditure contributed $218.68 \%$. That is to say though the energy efficiency has increased, but the expenditure on housing was growing sharply from 1990 to 2011.

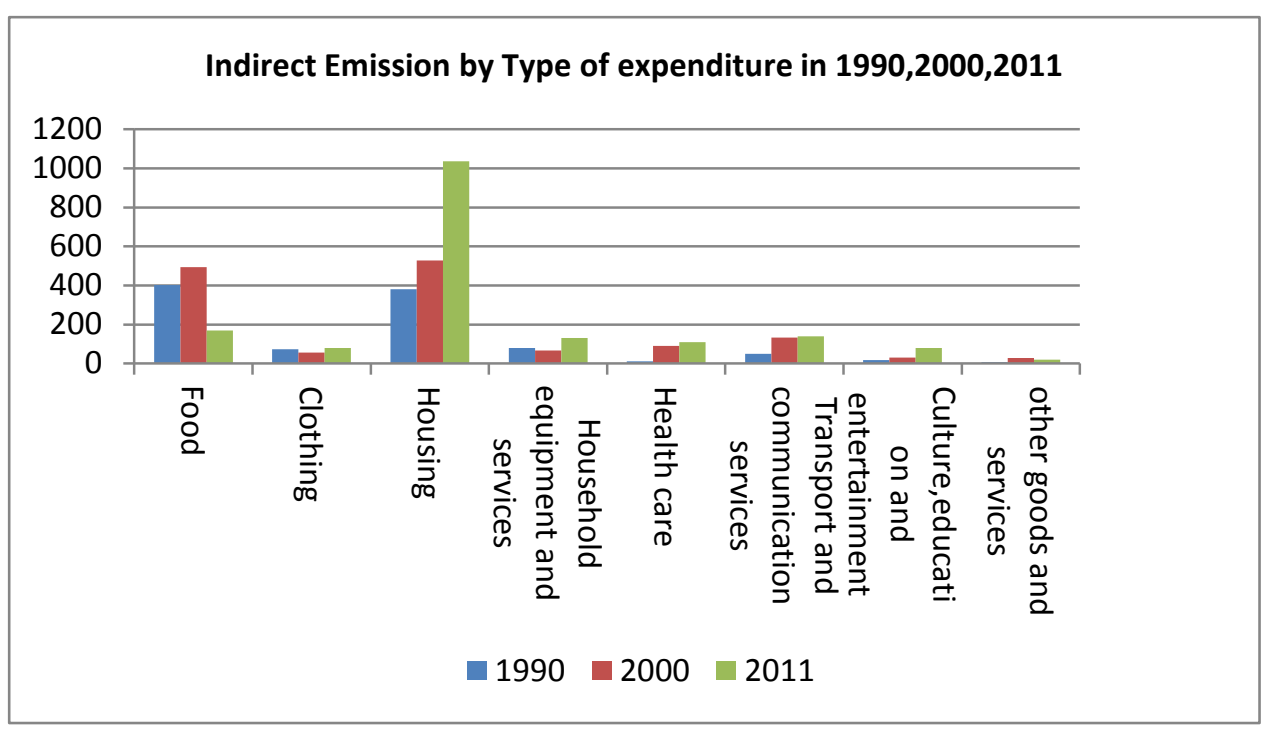

Figure 8. The indirect emission by type of expenditure in 1990, 2010, 2011

\section{Conclusion - Rural Sustainable Energy Consumption}

This paper is an initial study on societal dimension of energy consumption which is from the nexus approach - nexus of social inequity, household energy use, and environmental vulnerability toward equitable and sustainable urbanization process. It stress that access to clear energy for the rural household and emission control in rural region should be integrated into the city cluster development plan in urbanization process. This study may have high relevant for other emerging economies in the developing world.

According to our result, it obviously recognizes the current patters of rural household energy residential energy are drives for unsustainable trend, although it has been changed with more sustainable manner over the last two decades. The results have explored the interlinked the household income inequality and environmental inequality \& vulnerability between rural and urban household. The high rural emission and un-commercial energy residential energy use, its root of social problem arising from income inequality and failed public infrastructure. From the energy emission point of view, the effect of the decreasing emission intensity couldn't offset the increasing household expenditure on indirect emissions particularly. The results indicate that almost half rural family still use no-commercial energy and thus coal is the main commercial energy sources; the per capital $\mathrm{CO} 2$ emissions of rural region is much higher than urban region, which is driven by low energy efficiency and less advanced public infrastructure.

The main challenges for environmental inequality of the rural region which driven from our analysis results are as the flowing:

1) Still in 2015 urban households spent 21392 Yuan (2.32 times) more than rural households; and urban households received 31195 Yun (2.73 times) more in yearly income than rural households. This urban-rural income gap has played an increasingly important role in income inequality as well as for environmental inequality in China as a whole.

2) The use of non-commercial energy such as straw and firewood is till major rural residential energy resource, and the proportion of no-commercial energy by rural household has been keep consistent with sharing of $43 \%$ in total energy use over last 20 years. Because of the traditional use of non-commercial energy - direct burning, the non-commercial energy efficiency is lower than the commercial energy. This will lead to the shortage of the energy in rural and increase of emissions. It is imperative to change the non-commercial energy into energy which has high efficiency and low emission factor through some technology, such as the gasification of the straw, straw power 
generation. To promoting sustainability and equity between urban and rural region, the access to clear energy for rural population must be addressed, and the rural emission control should be integrated into the China city cluster development plan, particularly to reduce the non-commercial energy emission in rural region. Only this urban/rural inclusive development manner can envision an evolution toward equitable and sustainable development between rural-urban regions.

2) Even within the commercial energy source, per capita household use of electricity, natural gas, coal gas, and liquefied petroleum gas is also lower than national levels. This suggests that demand for high-quality energy sources has great potential for growth in the countryside. Especially the electricity, so to low the emission factor of the electricity is the main way to decrease the direct emission. The hydro and solar energy is very rich in countryside. The government should give some policy support and provide the financial support such as low price and low tax for the development of the small-scale hydro and solar power in countryside.

In rural China Coal is still the main type of commercial energy use, which is used for cooking and heating. The average thermal efficiency of cooking stoves and heating is relatively low. To improve the utilization efficiency of the coal is the main way to decrease the consumption of the coal and direct emission. Under the circumstances, more integrated and systemic approaches for reformative cook stove programs need to be implemented. Moreover, $60 \%$ of China's buildings in rural areas are made from clay bricks which have poor insulating qualities, combined with lack of the central heating system, it will require more energy for heating, Promoting efficient rural buildings and the implement of the central heating system should be introduced.

The policy to promote the sustainable energy consumption in rural China, our main consideration with addressing on two dimensions:

1) Policy for reducing the environment inequality should focus on energy affordability and promoting a transition away from biomass to other modern energy sources. With the rapid development of rural economic and urbanization, it's urgent to make shift from the high ratio of coal consumption and un-commercial energy to modern energy by enabling services such as lighting, heating, transport, communication, and mechanical power. Improving access to these services in the rural areas of China remains a major challenge. The share of expense for household facilities and articles in per capita consumption of clean Energy in rural areas should be facilitated in national energy policy.

2) Promoting efficient rural buildings and infrastructure. Urbanization process emerges numerous environmental problems, such as heavy traffic, air pollution. Thus, one available choice is to promote the energy infrastructure in rural areas and to advocate the use of clean cooking facilities with higher energy efficiency. The building of

Smart Grid will be another wise choice for the access to modern energy services in rural areas, which helps to reduce the inefficiency of electricity supply by traditional power networks. It is most important to change the energy structure and improve the energy efficiency, such as to generate electricity using renewable technologies and to replace coal with modern biomass energy for cooking and heating, Still $60 \%$ of China's buildings are in rural areas, made from clay bricks which have poor insulating qualities and require more energy to produce (UNDP, 2014). At present efforts to modernize rural practices are constrained by financial access and technical capacity. There is great room for mandatory energy-efficient measures and reducing emission to be introduced to buildings.

3) Increasing farmers' awareness of environmental protection

It is not necessarily about consuming less; it is about consuming better more efficiently, with less risk to people health and environment in energy use related to the rural lifestyle. In rural area of China, traditional energy resources are usually used during a long period partly due to low educational level of farmers and weak awareness of environment protection. To reduce over-exploitation of biomass resources and optimizing the structure of energy consumption, it is crucial to rise farmers' awareness of environmental protection and acceptability of advanced cook stove.

\section{References}

Alam, M., Sathaye, J., \& Barnes, D. (1998). Urban household energy use in India: efficiency and policy implications. Energy Policy, 26(11), 885-891. https://doi.org/10.1016/S0301-4215(98)00008-1

And, D. F. B., \& Floor, W. M. (2003). Rural energy in developing countries: a challenge for economic development1. Social Science Electronic Publishing, 21(1), 497-530.

Bin, S., \& Dowlatabadi, H. (2005). Consumer lifestyle approach to US energy use and the related $\mathrm{CO}_{2}$ emissions. Energy Policy, 33(2), 197-208. https://doi.org/10.1016/S0301-4215(03)00210-6

Boxall, P. C., Chan, W. H., \& Mcmillan, M. L. (2005). The impact of oil and natural gas facilities on rural residential property values: a spatial hedonic analysis. Working Papers, 27(3), 248-269. https://doi.org/10.1016/j.reseneeco.2004.11.003 
Campbell, B.M., S.J. Vermeulen, J.J. Mangono, \& R. Mabugu. (2003). The energy transition in action: Urban domestic fuel choices in a changing Zimbabwe. Energy Policy, 31(6), 553-562. https://doi.org/10.1016/S0301-4215(02)00098-8

Clark A. Miller, Alastair Iles, \& Christopher F. Jones. (2013). The social dimensions of energy transitions. Science As Culture, 22(2), 135-148. https://doi.org/10.1080/09505431.2013.786989

Heltberg, R., Arndt, T. C., \& Sekhar, N. U. (2000). Fuelwood consumption and forest degradation: a household model for domestic energy substitution in rural india. Land Economics, 76(2), 213-232. https://doi.org/10.2307/3147225

Intergovernmental Panel on Climate Change. (2011). Sustainable Development and Equity. Intergovernmental Panel on Climate Change. Retrieved from https://www.ipcc.ch/pdf/assessment-report/ar5/wg3/ipcc_wg3_ar5_chapter4.pdf

Leontief, W. (1936). Composite commodities and the problem of index numbers. Econometrica, 4(1), 39-59. https://doi.org/10.2307/1907120

Madubansi, M., \& Shackleton, C. M. (2007). Changes in fuelwood use and selection following electrification in the bushbuckridge lowveld, south africa. Journal of Environmental Management, 83(4), 416-26. https://doi.org/10.1016/j.jenvman.2006.03.014

Maurizio Cellura, Alessandra Di Gangi, Sonia Longo, et al. (2013). An Italian input-output model for the assessment of energy and environmental benefits arising from retrofit actions of buildings. Energy and Buildings, 62, 97-106. https://doi.org/10.1016/j.enbuild.2013.02.056

Miller, C. (2012, May) Energy justice: Ensuring human dignity in the post-carbon future. Cairo Review of Global Affairs, 46-59.

Modi, V., Mcdade, S., Lallement, D., Saghir, J., Modi, V., \& Mcdade, S., et al. (2005). Energy services for the Millennium Development Goals.

National Development and Reform Commission People's Republic of China. (2004). Initial National Climate Change Home Information Bulletin. Beijing: China Planning Press.

National Development and Reform Commission People's Republic of China Initial National Climate Change Home Information Bulletin. China Planning Press, Beijing, China, 2004.

O'Rourke, D., \& Connolly, S. (2003). Just oil? the distribution of environmental and social impacts of oil production and consumption. Annual Review of Environment \& Resources, 28(28), 587-617. https://doi.org/10.1146/annurev.energy.28.050302.105617

Ouedraogo, B. (2006). Household energy preferences for cooking in urban ouagadougou, burkina faso. Energy Policy, 34(18), 3787-3795. https://doi.org/10.1016/j.enpol.2005.09.006

Reinders, A.H.M.E., Vringer, K., \& Blok, K. (2003). The direct and indirect energy requirement of households in the European Union. Energy Policy,31, 139-153. https://doi.org/10.1016/S0301-4215(02)00019-8

Richard Cowell, Gill Bristow, \& Max Munday. (2011). Acceptance, acceptability and environmental justice: the role of community benefits in wind energy development. Journal of Environmental Planning \& Management, 54(4), 539-557. https://doi.org/10.1080/09640568.2010.521047

State Statistical Bureau of China. (1991-2012). China energy statistical yearbook 1991-2012. Beijing: China Statistical Press.

State Statistical Bureau of China. (1991-2012). China statistical yearbook. (1991-2012). Beijing: China Statistical Press.

State Statistical Bureau of China. (2016). China statistical yearbook China National 2016. Beijing: China Statistical Press.

Sustainable Energy Authority of Ireland. (2016). Emission Factor from Sustainable Energy Authority of Ireland. Retrieved from http://www.seai.ie/Publications/Statistics_Publications/Emission_Factors/

U.S Energy Information Administration, Voluntary Reporting of Greenhouse Gases Program. Retrieved from http://www.eia.gov/oiaf /1605/ee-factors.html

UNDP N. Y. E. (2000). World energy assessment: energy and the challenge of sustainability, 77(2), 436-438.

Wang, MeiCheng. (2006). A comparative multivariate analysis of household energy requirements in australia, brazil, denmark, india and japan. Energy, 31(2-3), 181-207. 